\title{
Prevalence and Predictors of Malaria in Human Immunodeficiency Virus Infected Patients in Beira, Mozambique
}

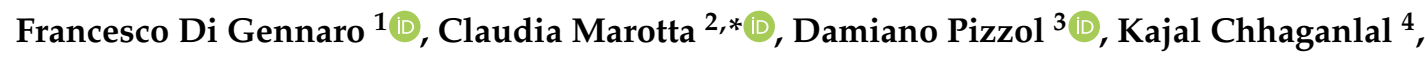 \\ Laura Monno ${ }^{1}$, Giovanni Putoto ${ }^{5}$, Annalisa Saracino ${ }^{1}$, Alessandra Casuccio ${ }^{2} \mathbb{C}$ \\ and Walter Mazzucco ${ }^{2}$ (D) \\ 1 Department of Infectious Diseases, University of Bari “Aldo Moro”, 35128 Bari, Italy; \\ cicciodigennaro@yahoo.it (F.D.G.); laura.monno@uniba.it (L.M.); annalisa.saracino@uniba.it (A.S.) \\ 2 Department of Science for Health Promotion and Mother to Child Care "G. D'Alessandro", via del Vespro, \\ University of Palermo, 90217 Palermo, Italy; alessandra.casuccio@unipa.it (A.C.); \\ walter.mazzucco@unipa.it (W.M.) \\ 3 Doctors with Africa-CUAMM, Research Unit, Beira 1363, Mozambique; d.pizzol@cuamm.org \\ 4 Center for Research in Infectious Diseases, Faculty of Health Sciences, Catholic University of Mozambique, \\ Beira 1363, Mozambique; kajal83bc@yahoo.com \\ 5 Research Section, Doctors with Africa CUAMM, 35128 Padova, Italy; g.putoto@cuamm.org \\ * Correspondence: marotta.claudia@gmail.com; Tel.: +39-333-798-4116
}

Received: 31 July 2018; Accepted: 14 September 2018; Published: 17 September 2018

\begin{abstract}
Co-infection between malaria and HIV has major public health implications. The aims of this study were to assess the malaria prevalence and to identify predictors of positivity to malaria Test in HIV positive patients admitted to the health center São Lucas of Beira, Mozambique. A retrospective cross-sectional study was performed from January 2016 to December 2016. Overall, 701 adult HIV patients were enrolled, positivity to malaria test was found in 232 (33.0\%). These patients were found to be more frequently unemployed $(76.3 \%)$, aged under $40(72.0 \%)$, with a HIV positive partner $(22.4 \%)$ and with a CD4 cell count $<200(59.9 \%)$. The following variables were predictors of malaria: age under 40 (O.R. $=1.56$; $95 \%$ CI: $1.22-2.08)$, being unemployed (O.R. $=1.74$; 95\%CI: 1.24-2.21), irregularity of cotrimoxazole prophylaxis's (O.R. $=1.42 ; 95 \% \mathrm{CI}: 1.10-1.78)$, CD4 cell count $<200$ (O.R. $=2.01 ; 95 \%$ CI: $1.42-2.32)$ and tuberculosis comorbidity (O.R. $=1.58 ; 95 \% C I: 1.17-2.79)$. In conclusion, high malaria prevalence was found in HIV patients accessing the out-patients centre of São Lucas of Beira. Our findings allowed us to identify the profile of HIV patients needing more medical attention: young adults, unemployed, with a low CD4 cell count and irregularly accessing to ART and cotrimoxazole prophylaxis.
\end{abstract}

Keywords: malaria prevalence; HIV; HIV-malaria co-infection; malaria predictors in developing countries; cotrimoxazole prophylaxis; Mozambique

\section{Introduction}

Despite improvements, malaria and acquired immune deficiency syndrome (AIDS) are two of the most important infectious diseases worldwide [1]. Malaria is on the list of AIDS-related opportunistic infections and the highest occurrence of human immunodeficiency virus (HIV) and malaria cases are reported in sub-Saharan countries [2]. Particularly, HIV infection is expected to increase the morbidity and mortality attributed to malaria, reducing the immune response against Plasmodium spp. and, consequently, leading to a more frequent occurrence of clinically severe malaria cases [3]. Interestingly, 
the use of cotrimoxazole (CTX) prophylaxis and antiretroviral therapy (ART) in HIV-infected patients seems to provide a protective effect from malaria [4].

Mozambique is one of the sub-Saharan African countries with the highest incidences of HIV co-infection associated to endemic malaria [5,6]. In Mozambique, Plasmodium falciparum infection accounts for $90 \%$ of all malaria cases, followed by P. malariae and P. ovale responsible of about $9 \%$ and $1 \%$, respectively. In 2015, the confirmed cases of malaria were 8,520,376 [5]. Furthermore Mozambique has one of the highest incidences of HIV worldwide with an estimated national prevalence of $12.5 \%$ in the age-group 15-49 and the estimated number of deaths of 62,000/years [6].

However, the number of studies on prevalence and clinical manifestations of HIV- malaria co-infection in Mozambique is limited [7,8]. The aims of our study were: (i) to verify the prevalence of malaria in HIV patients and (ii) to identify predictors of positivity to malaria test in HIV patients admitted to the health center of São Lucas of Beira, the second largest city of Mozambique.

\section{Materials and Methods}

A retrospective observational cross-sectional study was designed and implemented to analyze data of patients accessed the health centre of São Lucas of Beira, Sofala, Mozambique, from January 2016 to December 2016.

The health center of São Lucas provides access to free care and treatment of HIV / AIDS patients in an out-patients setting. For each new admitted patient, medical history is collected and the HIV status is checked with the HIV Rapid Test and, if positive, confirmed by western blot. Each consecutive consultation includes full clinical examination, (including HIV status according to WHO), ART therapy, cotrimoxazole prophylaxis, CD4+ T cell count, partner HIV status, co-morbidities (diabetes, hypertension and tuberculosis) and other sexual transmitted infections (STI), including genital herpes, condyloma, syphilis, gonorrhea and candidiasis. With regard to ART therapy and cotrimoxazole prophylaxis, information on regularity of their administration are also collected. In case of clinical suspicion of diabetes or tuberculosis, specific diagnostic protocol according to WHO guidelines is applied to confirm the diagnosis [9].

Malaria screening is performed using the Malaria Rapid Diagnostic Test (RDT) kit, as described by the manufacturer's (Standard Diagnostics Bioline, 2013). The confirmation of RDT results is obtained by blood smear microscopy [10]. All patients with a positive malaria blood slide and/or rapid diagnostic test are considered as infected with malaria.

A sample size estimation was performed using the following formula [11]:

$$
\mathrm{n}=\frac{\mathrm{Z}^{2} \times \mathrm{p}(1-\mathrm{p})}{\mathrm{e}^{2}}
$$

where $\mathrm{Z}=1.96, \mathrm{p}=$ prevalence of malaria among people living with HIV (PLWHIV): 25.9\% [12], $\mathrm{e}=$ error rate: 0.05 .

A convenience sampling of at least 298 PLWHIV was estimated. All HIV / AIDS adult patients (>18 years) that consecutively accessed the health center for a medical consultation or to collect their antiretroviral (ARV) drugs from January 2016 to December 2016 were identified through the patients' registry and were recruited in the study.

\subsection{Statistical Analysis}

Categorical variables were reported as absolute and relative frequencies (percentages). Chi-square test (with the Yates' correction as required) was used to compare categorical variables. A logistic regression model was implemented as follows: Malaria positivity was considered as dependent variable and each one of the available factors at the baseline evaluation were used as independent variables (univariate analysis). In the multivariate analysis all the factors with a $p$-value $<0.10$ at the univariate analyses were included. Multicollinearity among covariates was assessed through the variance inflaction factor (VIF), taking a value of 2 for excluding a covariate. However, no variable was 
excluded according to the previous criterion. Odds Ratios (ORs) as adjusted Odds Ratios (Adj-ORs) with their $95 \%$ confidence intervals (CIs) were used to measure the association between factors at the baseline (exposure) and Malaria positivity (outcome).

All statistical tests were two-tailed and statistical significance was assumed for a $p$-value $<0.05$. Analyses were performed by using the SPSS 21.0 for Windows (SPSS Inc., Chicago, IL, USA).

\subsection{Ethics Approval}

Ethical approval of the protocol was achieved by District Health Authority in Beira, the Health District Direction (protocol reference: 189/17), Mozambique and (as this study used secondary data) informed patient consent was not required.

\section{Results}

A total of 701 adult HIV positive patients ( $n=430,61.3 \%$ females; $n=421,60.0 \%$ under 40 years old) were enrolled in the study. The demographic and HIV related characteristics, overall and according to the malaria test result (positive versus negative), are summarized in Table 1. A positive malaria test was found in $232(33.0 \%)$ patients. These patients, compared to the negative ones, were more frequently unemployed $(n=177 ; 76.3 \%)$, aged under $40(n=167 ; 72.0 \%)$, with a HIV positive partner $(n=52$; $22.4 \%)$ and with a CD4 cell count $<200(n=139 ; 59.9 \%)$, being all of these differences statistically significant ( $p$-value: $<0.05$ ). By contrast, malaria negative patients resulted were more frequently receiving cotrimoxazole prophylaxis $(n=302 ; 64.3 \%)$, under ART $(n=360 ; 77.2 \%)$, and to be more regular in taking it ART $(n=261 ; 72.5 \%)$ ( $p$-value: $<0.05)$. No statistical differences between the two groups were observed for gender ( $p$-value: 0.38 ) and HIV stage defined by the WHO ( $p$-value: 0.38 ).

Table 1. Demographic and HIV related characteristics of $701 \mathrm{HIV}$ positive patients, stratified by malaria test results.

\begin{tabular}{|c|c|c|c|c|}
\hline & \multirow{2}{*}{ Total } & \multicolumn{2}{|c|}{ Malaria Test Result } & \multirow{3}{*}{$p$-Value } \\
\hline & & Positive & Negative & \\
\hline & n. $701(100 \%)$ & n. $232(33.0 \%)$ & n. $469(77.0 \%)$ & \\
\hline \multicolumn{5}{|l|}{ Sex } \\
\hline Female & $430(61.3)$ & $137(59.0)$ & $293(62.5)$ & \multirow{2}{*}{0.38} \\
\hline Male & $271(38.7)$ & $95(41.0)$ & $176(37.5)$ & \\
\hline \multicolumn{5}{|l|}{ Age } \\
\hline$<40$ years & $421(60.05)$ & $167(72.0)$ & $254(54.1)$ & \multirow{2}{*}{$<0.05$} \\
\hline$\geq 40$ years & $280(39.95)$ & $65(28.0)$ & $215(45.9)$ & \\
\hline \multicolumn{5}{|l|}{ Occupation } \\
\hline Unemployed & $350(49.92)$ & $177(76.3)$ & $173(36.8)$ & \multirow{2}{*}{$<0.05$} \\
\hline Employed & $351(50.07)$ & $55(23.7)$ & $296(63.2)$ & \\
\hline \multicolumn{5}{|l|}{ Partner' HIV status } \\
\hline Positive & $79(11.3)$ & $52(22.4)$ & $27(5.8)$ & \multirow{3}{*}{$<0.05$} \\
\hline Negative & $281(40.0)$ & $110(47.4)$ & $171(36.4)$ & \\
\hline Missing & $341(48.7)$ & $70(30.2)$ & $271(57.8)$ & \\
\hline \multicolumn{5}{|l|}{ HIV Stage by WHO } \\
\hline I-II & $322(45.93)$ & $112(48.2)$ & $210(44.7)$ & \multirow{3}{*}{$<0.05$} \\
\hline III-IV & $379(54.07)$ & $120(51.8)$ & $259(55.3)$ & \\
\hline \multicolumn{4}{|l|}{ ART } & \\
\hline Yes & $463(66.1)$ & $103(44.3)$ & $360(77.2)$ & \multirow[b]{2}{*}{$<0.05$} \\
\hline No & $238(33.9)$ & $129(55.7)$ & $109(22.8)$ & \\
\hline \multicolumn{5}{|l|}{ Regularity of ART } \\
\hline Yes & $271(58.53)$ & $10(19.4)$ & $261(72.5)$ & \multirow[b]{2}{*}{$<0.05$} \\
\hline No & $192(41.47)$ & $93(80.6)$ & $99(27.5)$ & \\
\hline
\end{tabular}


Table 1. Cont.

\begin{tabular}{|c|c|c|c|c|}
\hline & \multirow{2}{*}{ Total } & \multicolumn{2}{|c|}{ Malaria Test Result } & \multirow{3}{*}{$p$-Value } \\
\hline & & Positive & Negative & \\
\hline & n. $701(100 \%)$ & n. $232(33.0 \%)$ & n. $469(77.0 \%)$ & \\
\hline \multicolumn{5}{|c|}{ CD4+ T cell count } \\
\hline$<200$ & $245(34.9)$ & $139(59.9)$ & $106(22.6)$ & \multirow{2}{*}{$<0.05$} \\
\hline$>200$ & $456(65.1)$ & $93(40.1)$ & $363(77.4)$ & \\
\hline \multicolumn{5}{|c|}{ Cotrimoxazole prophylaxis } \\
\hline Yes & $353(50.3)$ & $51(22.0)$ & $302(64.3)$ & \multirow{2}{*}{$<0.05$} \\
\hline No & $348(49.7)$ & $181(88.0)$ & $167(35.7)$ & \\
\hline \multicolumn{5}{|c|}{ Regularity of cotrimoxazole prophylaxis } \\
\hline Yes & $251(71.10)$ & $10(19.6)$ & $241(79.8)$ & \multirow{2}{*}{$<0.05$} \\
\hline No & $102(28.90)$ & $41(80.4)$ & $61(20.2)$ & \\
\hline
\end{tabular}

Table 2 reports the distribution of co-morbidities, stratified by malaria test result. Considering the whole sample, hypertension was found in 83 patients $(11.8 \%)$, diabetes in $15(2.1 \%)$, tuberculosis in $97(13.8 \%)$ and other STIs in 188 (26.8\%). Comparing the two groups, patients were more frequently affected by tuberculosis in the malaria positive group (n.61; 26.3\%) ( $p$-value: $<0.05$ ). Conversely, no statistically significant difference was highlighted between the two groups for hypertension, diabetes and other STIs.

Table 2. Distribution of co-morbidities among the $701 \mathrm{HIV}$ positive patients enrolled, stratified by Malaria test results.

\begin{tabular}{|c|c|c|c|c|}
\hline & \multirow{2}{*}{ Total } & \multicolumn{2}{|c|}{ Malaria Test Result } & \multirow{3}{*}{$p$-value } \\
\hline & & Positive & Negative & \\
\hline & $n=701(100 \%)$ & $n=232(33.0 \%)$ & $n=469(77.0 \%)$ & \\
\hline \multicolumn{5}{|c|}{ Hypertension } \\
\hline Yes & $83(11.84)$ & $21(9.0)$ & $62(13.2)$ & \multirow{2}{*}{0.10} \\
\hline No & $618(88.15)$ & $211(91.0)$ & $407(86.8)$ & \\
\hline \multicolumn{5}{|c|}{ Diabetes } \\
\hline Yes & $15(2.13)$ & $3(1.3)$ & $12(2.3)$ & \multirow{2}{*}{0.41} \\
\hline No & $686(97.86)$ & $229(98.7)$ & $457(97.7)$ & \\
\hline \multicolumn{5}{|c|}{ Tuberculosis } \\
\hline Yes & $97(13.83)$ & $61(26.3)$ & $36(7.7)$ & \multirow[b]{2}{*}{$<0.05$} \\
\hline No & $604(86.16)$ & $171(73.7)$ & $433(92.3)$ & \\
\hline \multicolumn{5}{|c|}{ Other STI * } \\
\hline Yes & $188(26.81)$ & $71(30.6)$ & $117(24.9)$ & \multirow{2}{*}{0.13} \\
\hline No & $513(73.18)$ & $161(69.4)$ & $352(75.1)$ & \\
\hline
\end{tabular}

The multivariate model considered the effects on malaria (dependent variable) of age ( $<40$ years old), occupational status (unemployed), partner HIV positivity, being under ART, regularity of ART, CD4+ T cell count $<200$, being under cotrimoxazole prophylaxis, irregularity of cotrimoxazole prophylaxis and presence of tuberculosis comorbidity. The following variables resulted predictive of malaria positivity (Table 3): age under 40 (O.R. $=1.56$; 95\%CI: 1.22-2.08), being unemployed $(\mathrm{O} . \mathrm{R} .=1.74 ; 95 \% \mathrm{CI}: 1.24-2.21)$, irregularity of cotrimoxazole prophylaxis $(\mathrm{O} . \mathrm{R} .=1.42 ; 95 \% \mathrm{CI}$ : 1.10-1.78), CD4 cell count $<200$ (O.R. $=2.01 ; 95 \%$ CI: 1.42-2.32) and tuberculosis comorbidity (O.R. $=1.58 ; 95 \%$ CI: $1.17-2.79)$. 
Table 3. Predictors of positivity at Malaria Test in HIV positive patients.

\begin{tabular}{ccc}
\hline Characteristics & Univariate Analysis OR & Multivariate Analysis Adj-OR \\
\hline Age $<40$ & $1.28(1.06-1.78)$ & $1.56(1.22-2.08)^{*}$ \\
Partners HIV positivity & $0.36(0.08-0.83)$ & $0.42(0.08-1.03)$ \\
Unemployed & $1.85(1.35-2.45)$ & $1.74(1.24-2.21)^{*}$ \\
ART & $0.64(0.38-0.78)$ & $0.74(0.50-1.03)$ \\
Regularity of ART & $0.75(0.49-0.92)$ & $0.51(0.28-0.85)$ \\
CD4+ T cell count $<200$ & $1.91(1.34-2.19)$ & $2.01(1.42-2.32)^{*}$ \\
Cotrimoxazole prophylaxis & $0.53(0.41-0.83)$ & $0.58(0.43-0.90)$ \\
Irregularity of Cotrimoxazole & $1.80(1.50-2.00)$ & $1.42(1.10-1.78) *$ \\
prophylaxis & $1.31(1.06-1.66)$ & $1.58(1.17-2.79) *$ \\
Tuberculosis & &
\end{tabular}

* Statistically significant values; OR: Odds Ratio; Adj-OR: Adjusted Odds Ratio; ART: antiretroviral therapy.

\section{Discussion}

This cross-sectional study aimed to estimate the prevalence of malaria and to identify its predictors in HIV patients accessing to the health center of São Lucas of Beira, an endemic malaria area. Malaria and HIV are two of the most challenging global health issues for developing countries, especially for Mozambique, where malaria accounts for $29 \%$ of all deaths, closely followed by AIDS, responsible of $27 \%$ of the mortality in the general population $[13,14]$. Moreover, it is well know that these two infectious diseases are closely linked each other. In HIV patients, during malaria co-infection, it has been reported to cause an increase in plasma HIV-1 RNA levels and a decline in the CD4+ T cell count [15]. On the other hand, HIV co-infection is associated with increased mortality in areas of stable malaria transmission, making both malaria severity and HIV important risk factors for death [16].

However, to the best of our knowledge, only a few studies have evaluated the epidemiological aspects of HIV and Malaria co-infection in Mozambique [12-17], and none of them have explored the HIV non-hospitalized population.

Malaria prevalence in our study population was $33.0 \%$, being higher when compared to the $25.9 \%$ reported among HIV patients hospitalized at Central Hospital of Beira and to the $9.8 \%$ of HIV patients hospitalized at Central Hospital of Maputo in 2008 [17]. In the same direction, our study documented a higher malaria occurrence, if compared to similar studies conducted in other developing countries, such as Ghana (11.75\%) [18], and Nigeria (18.5\%) [19]. These differences could be due to the different study periods, considering that malaria transmission is seasonal, and has different endemicity levels.

Moreover, although it is well known than HIV patients are more susceptible to malaria, in this study we identified a further more vulnerable group, consisting of young and unemployed patients with a low CD4 cell count, irregular in taking cotrimoxazole prophylaxis and with a previous history of tuberculosis. This evidence is in line with the current literature [20,21]. In fact, correlation between age and level of malaria transmission is well known also among HIV negative patients: IgG levels, tending to increase with the age [22-24], influence the severity of malaria and immune response.

Again, according to the literature, the patients enrolled in our study undergoing regularly to ART were less susceptible to malaria. This effect could be explained by the non-adherence to ART that can increase the risk of opportunistic infection such as malaria, being included in the list of AIDS-related opportunistic infections by CDC since 2009 [25,26]. Likewise, also cotrimoxazole prophylaxis was just described as an important factor in reducing malaria incidence [12] and our data confirmed this hypothesis. Of interest, $\mathrm{WHO}$ recommends to stop cotrimoxazole in clinically stable patients with evidence of immune recovery and/or viral suppression under ART, while it should be continued in patients living in areas with high malaria and bacterial infection prevalence [27].

Another aspect emerging from our data is the role played by tuberculosis and health determinants such as socio-economic status in the interaction between HIV and malaria [28]. In fact, it is clear that poverty represents one of the major obstacle to the global burden control, leading to unfavourable outcomes most of all in these categories of patients [29-31]. Finally, our study also confirmed that 
having a HIV positive partner is a risk factor for malaria, since the behavioural determinant could be correlated both in the HIV transmission between the couple, the adherence to the ART therapy, the prophylaxis with cotrimoxazole and the proper use of the mosquito net [32-37]. On this basis, an appropriate couple-based care strategy should be integrated and implemented at the same time HIV behavioural and medical interventions. However, a further comparison with HIV negative patients could have been useful in order to better understand of the role of the HIV infection itself in the differences reported. Unfortunately, information on HIV negative patients were not available from our database.

The major limitations of this study are related to the cross-sectional design and to the typology of patients included in the study: since the study enrolled non-hospitalized patients, the possibility of self-medication for malaria could have biased the prevalence detected. In addition, the lack of data on pregnancy status, haemoglobin values and other health outcomes, did not allow a more comprehensive interpretation of results, so when HIV and malaria infection occur together a higher risk of complications should be considered.

Our findings allowed us to identify the profile of HIV patient needing more medical attention: young adults, unemployed, with a low CD4 cell count and irregularly accessing to ART and cotrimoxazole prophylaxis.

\section{Conclusions}

Despite the noted limitations, our study documented a very high malaria prevalence in a population of HIV subjects accessing an out-patients center in Mozambique, allowing us, at the same time, to better understand the profile of these patients that are highly vulnerable to co-infection. These findings could assist decision makers in efforts to plan HIV and malaria prevention interventions in low income countries and in settings with high endemicity. In particular, a more extensive use of cotrimoxazole for preventing and protecting opportunistic infections associated to malaria should be advocated with regard to young and unemployed HIV patients.

Author Contributions: All individuals who are listed as authors have contributed substantially to designing, performing, or reporting the study, and every specific contribution is indicated as follows: conception and design of the study: C.M., D.P., F.D.G., G.P., W.M.; statistical analysis: C.M., D.P., F.D.G., W.M.; interpretation of the data: C.M., D.P., F.D.G., G.P., W.M.; manuscript writing and drafting: C.M., D.P., F.D.G., G.P., W.M.; revision of the manuscript: C.M., G.M., L.M., A.S., D.P., F.D.G., G.P., K.C., W.M., A.C.; approval of the final version of the manuscript: C.M., D.P., F.D.G., G.P., A.C., W.M.

Funding: This research received no external funding.

Conflicts of Interest: The authors declare no conflict of interest.

\section{References}

1. Flateau, C.; Le Loup, G.; Pialoux, G. Consequences of HIV infection on Malaria and therapeutic implications: A systematic review. Lancet Infect. Dis. 2011, 11, 541-556. [CrossRef]

2. Murray, C.J.; Rosenfeld, L.C.; Lim, S.S.; Andrews, K.G.; Foreman, K.J.; Haring, D.; Fullman, N.; Naghavi, M.; Lozano, R.; Lopez, A.D. Global Malaria mortality between 1980 and 2010: A systematic analysis. Lancet 2012, 379, 413-431. [CrossRef]

3. Cuadros, D.F.; Branscum, A.J.; Crowley, P.H. HIV-Malaria co-infection: Effects of Malaria on the prevalence of HIV in East sub-Saharan Africa. Int. J. Epidemiol. 2011, 40, 931-939. [CrossRef] [PubMed]

4. Manyando, C.; Njunju, E.M.; D'Alessandro, U.; Van Geertruyden, J.P. Safety and efficacy of co-trimoxazole for treatment and prevention of Plasmodium falciparum Malaria: A systematic review. PLoS ONE 2013, 8, e56916. [CrossRef] [PubMed]

5. World Health Organization (WHO). Mozambique Malaria Country Profile 2015; WHO: Geneva, Switzerland, 2015.

6. World Health Organization (WHO). Mozambique HIV Country Profile 2016; WHO: Geneva, Switzerland, 2016. 
7. Berg, A.; Patel, S.; Aukrust, P.; David, C.; Gonca, M.; Berg, E.S.; Dalen, I.; Langeland, N. Increased Severity and Mortality in Adults Co-Infected with Malaria and HIV in Maputo, Mozambique: A Prospective Cross-Sectional Study. PLoS ONE 2014, 9, e88257. [CrossRef] [PubMed]

8. Ferrao, J.L.; Niquisse, S.; Mendes, J.M.; Painho, M. Mapping and Modelling Malaria Risk Areas Using Climate, Socio-Demographic and Clinical Variables in Chimoio, Mozambique. Int. J. Environ. Res. Public Health 2018, 19, 15. [CrossRef] [PubMed]

9. World Health Organization (WHO). Global Strategy and Targets for Tuberculosis Prevention, Care and Control after 2015; WHO: Geneva, Switzerland, 2014.

10. World Health Organization (WHO). Methods Manual for Malaria Microscopy, Method Identification and Qualification of Malaria in Thick and Thin Blood Film; WHO: Geneva, Switzerland, 2015.

11. Swinscow, T.D.V.; Campbell, M.J. Statistics at Square, 10th ed.; BMJ Books: London, UK, 2002.

12. Saracino, A.; Nacarapa, E.A.; da Costa Massinga, E.A.; Martinelli, D.; Scacchetti, M.; de Oliveira, C.; Antonich, A.; Galloni, D.; Ferro, J.J.; Macome, C.A. Prevalence and clinical features of HIV and Malaria co-infection in hospitalized adults in Beira, Mozambique. Malar. J. 2012, 26, 241. [CrossRef] [PubMed]

13. Mozambique. Malaria Operational Plan FY 2018. Available online: https:/ /www.pmi.gov/docs/defaultsource / default-document-library / Malaria-operational-plans / fy-2018 / fy-2018-mozambique-Malariaoperational-plan.pdf?sfvrsn $=5$ (accessed on 8 June 2018).

14. Marotta, C.; Di Gennaro, F.; Pizzol, D.; Madeira, G.; Monno, L.; Saracino, A.; Putoto, G.; Casuccio, A.; Mazzucco, W. The At Risk Child Clinic (ARCC): 3 Years of Health Activities in Support of the Most Vulnerable Children in Beira, Mozambique. Int. J. Environ. Res. Public Health 2018, 27, 15. [CrossRef] [PubMed]

15. Jegede, F.E.; Oyeyi, T.I.; Abdulrahman, S.A.; Mbah, H.A.; Badru, T.; Agbakwuru, C. Effect of HIV and Malaria parasites co-infection on immune-hematological profiles among patients attending anti-retroviral treatment (ART) clinic in Infectious Disease Hospital Kano, Nigeria. PLoS ONE 2017, 12, e0174233. [CrossRef] [PubMed]

16. Chalwe, V.; Van geertruyden, J.P.; Mukwamataba, D.; Menten, J.; Kamalamba, J.; Mulenga, M.; D’Alessandro, U. Increased risk for severe Malaria in HIV-1-infected adults, Zambia. Emerg. Infect. Dis. 2009, 15, 749-752. [CrossRef] [PubMed]

17. Berg, A.; Patel, S.; Langeland, N.; Blomberg, B. Falciparum Malaria and HIV-1 in hospitalized adults in Maputo, Mozambique: Does HIV-infection obscure the Malaria diagnosis? Malar. J. 2008, 7, 252. [CrossRef] [PubMed]

18. Tay, S.C.K.; Badu, K.; Mensah, A.A.; Gbedema, S.Y. The prevalence of Malaria among HIV seropositive individuals and the impact of the co- infection on their hemoglobin levels. Ann. Clin. Microbiol. Antimicrob. 2015, 14, 10. [CrossRef] [PubMed]

19. Ojurongbe, O.; Oyeniran, O.A.; Alli, O.A.T.; Taiwo, S.S.; Ojurongbe, T.A.; Olowe, A.O.; Opaleye, O.O.; Adeyeba, A.O. Prevalence of Plasmodium falciparum Parasitaemia and Its Correlation with Haematological Parameters among HIV-Positive Individuals in Nigeria. J. Trop. Med. 2014, 161284, 6. [CrossRef]

20. Moncunill, G.; Mayor, A.; Jiménez, A.; Nhabomba, A.; Puyol, L.; Manaca, M.N.; Barrios, D.; Cisteró, P.; Guinovart, C.; Aguilar, R.; et al. Age- and exposure-dependent immune responses during a Malaria episode may be key to understanding the role of these factors in the acquisition of immunity to Malaria. PLoS ONE 2013, 8, e55756.

21. Owusu, E.D.A.; Cofie, N.S.A.; Nai, E.A.; Klipstein-Grobusch, K.; Brown, C.A.; Mens, P.F.; Grobusch, M.P. Malaria, sickle cell disease, HIV and co-trimoxazole prophylaxis: An observational study. Int. J. Infect. Dis. 2018, 69, 29-34. [CrossRef] [PubMed]

22. Aguilar, R.; Ubillos, I.; Vidal, M.; Balanza, N.; Crespo, N.; Jiménez, A.; Nhabomba, A.; Jairoce, C.; Dosoo, D.; Gyan, B.; et al. Antibody responses to $\alpha$-Gal in African children vary with age and site and are associated with Malaria protection. Sci. Rep. 2018, 8, 9999. [CrossRef] [PubMed]

23. Atkinson, S.H.; Uyoga, S.M.; Armitage, A.E.; Khandwala, S.; Mugyenyi, C.K.; Bejon, P.; Marsh, K.; Beeson, J.G.; Prentice, A.M.; Drakesmith, H.; et al. Malaria and Age Variably but Critically Control Hepcidin Throughout Childhood in Kenya. EBioMedicine 2015, 2, 1478-1486. [CrossRef] [PubMed]

24. Grigg, M.J.; William, T.; Barber, B.E.; Rajahram, G.S.; Menon, J.; Schimann, E.; Piera, K.; Wilkes, C.S.; Patel, K.; Chandna, A.; et al. Age-Related Clinical Spectrum of Plasmodium knowlesi Malaria and Predictors of Severity. Clin. Infect. Dis. 2018, 67, 350-359. [CrossRef] [PubMed] 
25. Mermin, J.; Lule, J.; Ekwaru, J.P.; Malamba, S.; Downing, R.; Ransom, R.; Kigozi, A.; Nakanjako, D.; Wafula, W.; Quick, R.; et al. Effect of co-trimoxazole prophylaxis on morbidity, mortality, CD4-cell count, and viral load in HIV infection in rural Uganda. Lancet 2004, 364, 1428-1434. [CrossRef]

26. Centers for Disease Control and Prevention. Guidelines for prevention and treatment of opportunistic infections in HIV-infected adults and adolescents. mMWR 2009, 58, 94-98.

27. World Health Organization (WHO). Guidelines on Postexposure Prophylaxis for HIV and the Use of Co-Trimoxazole Prophylaxis for HIV-Related Infections among Adults, Adolescents and Children: Recommendations for a Public Health Approach; WHO: Geneva, Switzerland, 2014.

28. Di Gennaro, F.; Pizzol, D.; Cebola, B.; Stubbs, B.; Monno, L.; Saracino, A.; Luchini, C.; Solmi, M.; Segafredo, G.; Putoto, G.; et al. Social determinants of therapy failure and multi drug resistance among people with tuberculosis: A review. Tuberculosis 2017, 103, 44-51. [CrossRef] [PubMed]

29. Zeglin, R.J.; Stein, J.P. Social determinants of health predict state incidence of HIV and AIDS: A short report. AIDS Care 2015, 27, 255-259. [CrossRef] [PubMed]

30. Pizzol, D.; Veronese, N.; Marotta, C.; Di Gennaro, F.; Moiane, J.; Chhaganlal, K.; Monno, L.; Putoto, G.; Mazzucco, W.; Saracino, A. Predictors of therapy failure in newly diagnosed pulmonary tuberculosis casesin Beira, Mozambique. BMC Res. Notes 2018, 11, 99. [CrossRef] [PubMed]

31. Marotta, C.; Giaquinto, C.; Di Gennaro, F.; Chhaganlal, K.D.; Saracino, A.; Moiane, J.; Maringhini, G.; Pizzol, D.; Putoto, G.; Monno, L.; et al. Pathways of care for HIV infected children in Beira, Mozambique: Pre-post intervention study to assess impact of task shifting. BMC Public Health 2018, 18, 703. [CrossRef] [PubMed]

32. Jiwatram-Negrón, T.; El-Bassel, N. Systematic review of couple-based HIV intervention and prevention studies: Advantages, gaps, and future directions. AIDS Behav. 2014, 18, 1864-1887. [CrossRef] [PubMed]

33. Ogunmola, O.J.; Oladosu, Y.O.; Olamoyegun, M.A. Relationship between socioeconomic status and HIV infection in a rural tertiary health center. HIV AIDS 2014, 6, 61-67. [CrossRef] [PubMed]

34. Bunyasi, E.W.; Coetzee, D.J. Relationship between socioeconomic status and HIV infection: Findings from a survey in the Free State and Western Cape Provinces of South Africa. BMJ Open 2017, 7, e016232. [CrossRef] [PubMed]

35. Sonko, S.; Jaiteh, M.; Jafali, J.; Jarju, L.B.S.; D’Alessandro, U.; Camara, A.; Komma-Bah, M.; Saho, A. Does socio-economic status explain the differentials in malaria parasite prevalence? Evidence from The Gambia. Malar. J. 2014, 13, 449. [CrossRef] [PubMed]

36. Pizzol, D.; Di Gennaro, F.; Boscardin, C.; Putoto, G.; Cuppini, E.; Pita, G.; George, A.; Monno, L.; Saracino, A.; Da Dalt, L.; et al. Teenage pregnancies in Mozambique: The experience of "Servicios Amigos dos Adolescentes" clinics in Beira. Afr. J. AIDS Res. 2018, 17, 32-36. [CrossRef] [PubMed]

37. Yadav, K.; Dhiman, S.; Rabha, B.; Saikia, P.K.; Veer, V. Socio-economic determinants for malaria transmission risk in an endemic primary health centre in Assam, India. Infect. Dis. Poverty 2014, 3, 19. [CrossRef] [PubMed]

(C) 2018 by the authors. Licensee MDPI, Basel, Switzerland. This article is an open access article distributed under the terms and conditions of the Creative Commons Attribution (CC BY) license (http://creativecommons.org/licenses/by/4.0/). 